\title{
PERFIL DE RESISTÊNCIA DE CEPAS DE Staphylococcus COAGULASE POSITIVA ISOLADAS DE MANIPULADORES DE ALIMENTOS
}

\author{
SUZANA CLÁUDIA SILVEIRAMARTINS* \\ CLAUDIA MIRANDA MARTINS** \\ LAURÊNIAMARIABRAGAALBUQUERQUE*** \\ THATYANE VIDAL FONTELES $S^{* * * *}$ \\ SIMONE LOPES DO REGO***** \\ GENILTON DASILVAFAHEINAJUNIOR ${ }^{* * * * * *}$
}

\begin{abstract}
No presente trabalho, cepas de Staphylococcus coagulase positiva (SCP) de mãos de manipuladores de alimentos foram isoladas com 0 objetivo de avaliar o perfil de resistência dessas frente a diferentes quimioterápicos. Participaram deste estudo 100 manipuladores de uma indústria de processamento de alimentos, localizada em Fortaleza-CE. As colônias isoladas em Ágar BairdParker foram identificadas morfológica e bioquimicamente como sendo características do gênero Staphylococcus. Para a verificação da resistência a quimioterápicos utilizou-se o método de difusão em Ágar. Os resultados mostraram a presença de SCP em $24 \%$ dos manipuladores. A taxa de positividade foi mais elevada para o sexo feminino, com $79,17 \%$ das amostras analisadas. Verificou-se que $89 \%$ dos isolados foram resistentes à ampicilina e $86,6 \%$ à penicilina. Com relação à sensibilidade, $100 \%$ foram sensiveis ao sulfazotrim, $98,8 \%$ a nitrofurantoína, $97,6 \%$ à vancomicina, $96,3 \%$ ao cloranfenicol e $90,3 \%$ à ofloxacina. Observou-se resistência múltipla em $76 \%$ dos isolados, sendo que uma cepa foi resistente a oito antibióticos. A elevada ocorrência de resistência múltipla representa risco potencial para a saúde pública e pode dificultar o tratamento de doenças humanas e de animais, agravando quadros clínicos potencialmente curáveis.
\end{abstract}

PALAVRAS-CHAVE: AGENTES QUIMIOTERÁPICOS; RESISTÊNCIA BACTERIANA; S. aureus.

\footnotetext{
* Engenheira Química, Mestre em Tecnologia de Alimentos, Professora Adjunta, Universidade Federal do Ceará (UFC), Fortaleza, CE (e-mail: suzanac@ufc.br).

** Engenheira Agrônoma, Doutora em Agronomia (Ciências do Solo), Professora Adjunta, UFC, Fortaleza, CE (e-mail: claudiamartins@ufc.br).

*** Farmacêutica Bioquímica, Mestre em Microbiologia e Imunologia, Professora Adjunta aposentada, UFC, Fortaleza, CE (e-mail: laurenia@mdb.com.br).

**** Engenheira de Alimentos, Mestranda em Tecnologia de Alimentos, UFC, Fortaleza, CE (e-mail: thaty.vidal@gmail.com).

***** Engenheira de Alimentos, Mestranda em Tecnologia de Alimentos, UFC, Fortaleza, CE (e-mail: simonezen30@yahoo.com.br).

****** Graduando em Engenharia de Alimentos, UFC, Fortaleza, CE (e-mail: genilton@gmail.com).
} 


\section{INTRODUÇÃO}

A identificação de Staphylococcus em alimentos tem como objetivo a confirmação de surtos de intoxicação alimentar e o controle higiênico-sanitário dos processos de produção de alimentos, quando sua presença serve como indicador de contaminação pós-processo e das condições de sanificação da área de processamento (SENA, 2000; FRANCO e LANDGRAF, 2005).

Os primeiros surtos por toxinfecções estafilocócicas foram provocados por falhas na conservação dos alimentos e pela contaminação proveniente de manipulação incorreta (HOBS e ROBERTS, 1993; SILVEIRA et al., 2006). Dentre os fatores que contribuem para a proliferação de doenças causadas por alimentos em países desenvolvidos, $24 \%$ envolvem manipuladores que trabalham diretamente com alimentos (ARIAS-ECHANDI, 2000; ANDRADE, SILVA e BRABES, 2003). A intoxicação por S. aureus é oriunda da ingestão do alimento contendo as várias enterotoxinas $(A, B, C 1, C 2, C 3, D, E)$ sintetizadas por essa bactéria, que são capazes de resistir a tratamentos térmicos como a pasteurização (FRANCO e LANDGRAF, 2005).

O principal reservatório de estafilococos no homem são as fossas nasais, apesar de serem colonizadores de diferentes regiões do corpo como boca, trato intestinal e diversas áreas da pele, podendo atingir qualquer superfície ou objeto que entre em contato com essas zonas (MURRAY et al., 1992). CARVALHO e SERAFFINI (1996) citam que a partir dessas localizações, o microrganismo pode contaminar o alimento direta ou indiretamente, perpetuando a cadeia epidemiológica da intoxicação alimentar estafilocócica. Mesmo os manipuladores sadios abrigam bactérias que podem contaminar os alimentos pela boca, nariz, garganta e trato intestinal, assim como podem estar doentes ou serem portadores assintomáticos, ou mesmo apresentarem hábitos inadequados de higiene pessoal (CARDOSO, 1996; TAVARES, 2000; EVANGELISTA-BARRETO e VIEIRA, 2003).

Dentre o grande número de espécies de Staphylococcus, S. aureus é a espécie mais relacionada com casos de intoxicação alimentar. Porém, as espécies S. hyicus e S. intermedius também estão comumente associadas à doença humana. Por muito tempo, a espécie $S$. aureus foi considerada a única capaz de sintetizar enterotoxinas e coagulase. As outras duas espécies, também produtoras de enterotoxinas e de coagulase, foram identificadas posteriormente e incriminadas em surtos de intoxicação alimentar. Tal fato provocou alteração na legislação brasileira que passou a estabelecer a pesquisa e enumeração de estafilococos coagulase positiva, recomendando o uso de testes de coagulase como marcadores para virulência separando espécies diferentes de Staphylococcus (JAY, 2005; SILVA, JUNQUEIRA e SILVEIRA, 2001; TAVARES, 2000).

O tratamento das infecções estafilocócicas tem evoluído desde o início do surgimento dos antibióticos, como consequência da emergência da resistência e desenvolvimento de novas drogas antibacterianas. Pesquisas envolvendo o perfil de resistência a antibióticos de $S$. aureus, isolados de portadores humanos, comprovam que o uso indiscriminado desses agentes antimicrobianos representa problema crescente. O potencial patogênico desse microrganismo está relacionado com sua grande capacidade de mutação para formas mais resistentes frente aos antibióticos mais largamente utilizados. O surgimento de cepas resistentes aos antibióticos torna fundamental o desenvolvimento de novas drogas com atividade antimicrobiana e reavaliações periódicas no perfil de susceptibilidade (PEREIRA, SIQUEIRA JÚNIOR e TAKAKI, 2004; MOURA et al., 2006).

O presente trabalho teve como objetivo isolar cepas de Staphylococcus coagulase positiva (SCP) de mãos de manipuladores de uma indústria alimentícia e avaliar o perfil de resistência dessas cepas frente a diferentes quimioterápicos. Ressalte-se que segundo TAVARES (2000) a resistência das diversas espécies bacterianas aos antimicrobianos é extremamente variável entre os países, as regiões e a origem hospitalar ou comunitária das estirpes, enfatizando a importância dessa contribuição. 


\section{MATERIAL E MÉTODOS}

\subsection{AMOSTRAGEM}

Participaram deste estudo 100 manipuladores de alimentos, na faixa etária de 20 a 30 anos, sendo $57 \%$ mulheres e $43 \%$ homens que trabalham em uma indústria de processamento de alimentos localizada em Fortaleza-CE.

\subsection{COLETA DAS AMOSTRAS E ISOLAMENTO}

Coletaram-se amostras da superfície da palma e borda das mãos da seguinte forma: "swab", previamente umedecido em solução esterilizada de cloreto de sódio $0,85 \%$, foi deslizado de forma angular da parte inferior da palma das mãos (linha dos punhos) até a ponta dos dedos e voltando ao punho com movimentos rotatórios, repetidos três vezes na direção de cada dedo, passando pelas bordas da mão (CARVALHO e SERAFINI,1996). Em seguida, as amostras foram transportadas para o Laboratório de Microbiologia Ambiental do Setor de Microbiologia da Universidade Federal do Ceará, em caixas térmicas com gelo para realização das análises.

Para a contagem das Unidades Formadoras de Colônia (UFC) foram utilizadas duas diluições adequadas da amostra. Uma alíquota de $0,1 \mathrm{~mL}$ de cada diluição foi inoculada utilizando-se a técnica de spread plate, em duplicata, no meio de cultura Ágar Baird-Parker (DIFCO), adicionado de emulsão de gema de ovo e telurito de potássio. As placas foram incubadas a $37^{\circ} \mathrm{C}$ durante 48 horas. Foram selecionadas para a contagem, as placas contendo de 30 a 300 colônias típicas de $S$. aureus no meio seletivo-diferencial de acordo com as características culturais com a seguinte descrição: pequenas colônias circulares, pretas, lisas, convexas, com bordas perfeitas e rodeadas de zona opaca e/ou halo transparente em volta dessa zona opaca (SIQUEIRA, 1995; SENA, 2000; SILVA e GANDRA, 2004). As características morfológicas das cepas foram analisadas segundo a técnica de coloração de Gram.

\subsection{PROVAS DA CATALASE E COAGULASE}

As colônias típicas foram submetidas inicialmente ao teste da catalase, adicionando-se peróxido de hidrogênio $\left(\mathrm{H}_{2} \mathrm{O}_{2}\right) 3 \%$ sobre a colônia do microrganismo, cuja presença de bolhas caracteriza os estafilococos catalase positivos (PERESI et al., 2006). Posteriormente, para a detecção da atividade da enzima coagulase nas cepas que apresentaram positividade para o teste da catalase, utilizou-se o crescimento obtido em Brain Heart Infusion (BHI) incubado a $35^{\circ} \mathrm{C}$ por 24 horas. Em seguida, adicionou-se $0,5 \mathrm{~mL}$ de plasma de coelho, citratado e diluído a 1:5 em solução salina $(0,85 \%$ de $\mathrm{NaCl}$ em água; $\mathrm{p} / \mathrm{v})$ numa alíquota de $0,2 \mathrm{~mL}$ da cultura de cada cepa catalase positiva (FRANCO e LANDGRAF, 2005). Durante a incubação a $35^{\circ} \mathrm{C}$, os tubos foram observados quanto à formação de coágulo a cada 1 hora até completar 8 horas e depois após 24 horas. Os tubos que apresentaram formação de coágulo foram considerados positivos e as cepas com essa característica selecionadas.

\subsection{ANTIBIOGRAMA}

Para a verificação da resistência a quimioterápicos utilizou-se a técnica de difusão em Ágar, segundo BAUER et al. (1966). Empregaram-se os seguintes antibióticos: Ceftriaxona (30 $\mu \mathrm{g}$ ), Ofloxacina $(5 \mu \mathrm{g})$, Cloranfenicol $(30 \mu \mathrm{g})$, Cefatoxima $(30 \mu \mathrm{g})$, Oxacilina $(1 \mu \mathrm{g})$, Lincomicina $(2 \mu \mathrm{g})$, Ampicilina $(10 \mu \mathrm{g})$, Vancomicina $(30 \mu \mathrm{g})$, Nitrofurantoína (300 $\mu \mathrm{g})$, Penicilina (10 $\mu \mathrm{g})$, Tetraciclina (30 $\mu \mathrm{g})$ e Sulfazotrim $(25 \mu \mathrm{g})$ nas concentrações especificadas pelo National Committee for Clinical Laboratory Standards (LUES e TONDER, 2007). Para o controle de qualidade dos testes utilizou-se a cepa padrão de Staphylococcus aureus ATCC 23923 (American Type Culture Collection). 
Cada uma das cepas de SCP foi inoculada em placa com Ágar BHI (DIFCO) e incubada a $37^{\circ} \mathrm{C}$ por 24 horas. De 3 a 4 colônias foram retiradas e transferidas para tubos contendo caldo $\mathrm{BHI}$, em seguida incubados a $35^{\circ} \mathrm{C}$ até atingir a turbidez 0,5 da escala de Mac Farland (ICMSF, 1991).

As culturas foram semeadas mediante "swab" em placas com Ágar Müller-Hinton (DIFCO). Os discos de antibióticos foram colocados assepticamente nas placas que foram incubadas a $35^{\circ} \mathrm{C}$ de 16 a 18 horas (ZAVADINACK NETTO et al., 2001; BRESOLIN, DALL'STELLA e FONTOURA-DA-SILVA, 2005). As leituras foram realizadas por meio da medição dos halos de inibição, comparando-as posteriormente com os valores da tabela padrão quanto à susceptibilidade aos antimicrobianos testados (sensível ou resistente) (NCCLS, 2004).

\section{RESULTADOS E DISCUSSÃO}

Foram isoladas e caracterizadas 82 cepas de Staphylococcus coagulase positiva (SCP). A presença desse microrganismo foi verificada em $24 \%$ dos manipuladores. A taxa de positividade foi mais elevada para o sexo feminino, com $79,17 \%$ das amostras analisadas. ANDRADE et al. (2003) em trabalho semelhante observaram que $71,9 \%$ dos manipuladores apresentaram até $10^{2} \mathrm{UFC} /$ mão de SCP. VANZO e AZEVEDO (2003), EVANGELISTA-BARRETO e VIEIRA (2003), ANDRÉ et al. (2007) isolaram S. aureus de manipuladores de alimentos com índices (75\%, 60\% e $75 \%)$ superiores aos detectados no presente trabalho, levando-se em consideração os diferentes números de amostragem adotados.

LUES e TONDER (2007) encontraram S. aureus em 88\% das mãos de manipuladores de alimentos em uma "delicatessen". BRESOLIN, DALL'STELLAe FONTOURA-DA-SILVA (2005) efetuaram trabalho envolvendo 90 manipuladores. Detectaram S. aureus na mucosa nasal de 42 desses $(46,7 \%)$ com maior frequência entre os homens (60\%), e estabeleceram correlação entre a bactéria na mucosa nasal e nas mãos dos manipuladores. FIGUEROA, NAVARRETE e CARO (2002), pesquisando S. aureus enterotoxigênicos nas mãos de 102 manipuladores de alimentos verificaram incidência de $34 \%$, mas não detectaram diferença significativa entre o número de cepas isoladas entre os sexos masculino e feminino.

ASSUMPÇÃO et al. (2003) enfatizaram que a manipulação incorreta dos alimentos pode causar contaminação posterior, mesmo após o produto ser submetido a tratamento térmico. Os dados obtidos sobre a incidência de $S$. aureus em queijo prato mostraram que a população de SCP verificada nas mãos e antebraços de manipuladores seria a fonte de recontaminação do queijo analisado.

Os perfis de sensibilidade e resistência antimicrobiana das 82 cepas de SCP analisadas encontram-se na Tabela 1. O perfil de resistência em ordem decrescente ficou assim distribuído: $89 \%$ das cepas foram resistentes à ampicilina, $86,6 \%$ à penicilina, $69,5 \%$ à lincomicina, $39 \%$ à tetraciclina, $28 \%$ à cefotaxima e ceftriaxona, $13,4 \%$ à oxacilina, $9,7 \%$ ao cloranfenicol e à ofloxacina, $2,4 \%$ à vancomicina e apenas $1,2 \%$ à nitroforantoína.

O aparecimento de bactérias resistentes a antibióticos pode ser considerado como manifestação natural regida pelo princípio evolutivo da adaptação genética de organismos a mudanças no seu meio ambiente. Como o tempo de duplicação das bactérias pode ser de apenas 20 minutos existe a possibilidade de serem produzidas muitas gerações em apenas algumas horas, havendo, portanto, inúmeras oportunidades de adaptação evolutiva (SILVEIRA et al., 2006). TAVARES (2000) afirmou que a resistência para antibióticos pode ser explicada não apenas pela presença de genes de resistência, mas também pela expressão desses genes que é controlada pelo meio ambiente. De acordo com FELIX (2007), a resistência aos antimicrobianos observada em $S$. aureus pode ser codificada cromossomicamente ou mediada por plasmídio. 
TABELA 1- PERFIL DE SENSIBILIDADE E RESISTÊNCIA ANTIMICROBIANA DAS CEPAS DE Staphylococcus COAGULASE POSITIVA ISOLADAS DE MANIPULADORES DE ALIMENTOS

\begin{tabular}{c|c|c}
\hline Antimicrobiano & Sensível (\%) & Resistente (\%) \\
\hline Ampicilina & 11,0 & 89,0 \\
\hline Cefotaxima & 72,0 & 28,0 \\
\hline Ceftriaxona & 72,0 & 28,0 \\
\hline Cloranfenicol & 96,3 & 9,7 \\
\hline Lincomicina & 30,5 & 69,5 \\
\hline Nitroforantoína & 98,8 & 1,2 \\
\hline Ofloxacina & 90,3 & 9,7 \\
\hline Oxacilina & 86,6 & 13,4 \\
\hline Penicilina & 13,4 & 86,6 \\
\hline Sulfazotrim & 100 & 0 \\
\hline Tetraciclina & 61,0 & 39,0 \\
\hline Vancomicina & 97,6 & 2,4 \\
\hline
\end{tabular}

Na Figura 1 pode-se observar a comparação da resistência entre as cepas isoladas em relação aos antibióticos testados. Os mais altos índices de resistência foram detectados para a ampicilina $(89 \%)$, seguida pela penicilina ( $86,6 \%)$. Resultados semelhantes foram obtidos por VANZO e AZEVEDO (2003) e ACCO et al. (2003) a partir de cepas isoladas de manipuladores de alimentos, por MOURA et al. (2006) com linhagens isoladas de amostra de carne e BARBOSA, JORGE e UENO (2007) em cepas isoladas a partir de amostras de leite tipo $C$. A resistência à penicilina, também foi observada por ZAVADINACK NETTO et al. (2001) em cepas de SCP isoladas de abscessos cutâneos de origem comunitária. Estudos realizados em diversos países mostraram que a resistência à penicilina gira em torno de $60 \%$ (MOURA et al., 2006). TAVARES (2000) trabalhando com S. aureus isolados de carcaças de frango in natura observou elevada resistência às penicilinas, uma vez que geralmente esses microrganismos são resistentes aos quimioterápicos pertencentes ao grupo dos $\beta$-lactâmicos. Ressaltase que a ampicilina também pertence a esse grupo de antibióticos. Elevada resistência dos isolados aos antibióticos $\beta$-lactâmicos e particularmente à penicilina, segundo ACCO et al. (2003), seriam esperados devido ao seu uso generalizado no tratamento de infecções humanas. A evidência de alta taxa de resistência às penicilinas limita o uso desses quimioterápicos como alternativa na prevenção e tratamento de doenças ou toxinfecções estafilocócicas. Diante desse fato, o estudo de antibióticos como a oxacilina, resistentes às $\beta$-lactamases, são de grande importância e utilidade. VANZO e AZEVEDO (2003) e ACCO et al. (2003) encontraram sensibilidade em $100 \%$ das cepas isoladas de manipuladores de alimentos frente à oxacilina. No entanto, segundo BARBOSA et al. (2007), a ocorrência e disseminação de cepas resistentes a esse antibiótico é uma realidade preocupante.

No presente trabalho, a sensibilidade das cepas de Staphylococcus à oxacilina foi de $86,6 \%$ sendo observado percentual de 13,4 cepas resistentes. TAVARES (2000) considera que cerca de $80 \%$ das cepas de $S$. aureus isoladas do meio extra-hospitalar no Brasil mantêm boa sensibilidade à oxacilina. É importante registrar que para RODRIGUES et al. (1997) a incidência de S. aureus oxacilina resistente (ORSA) aumentou a partir da década de 80 , sendo considerado o principal agente clínico e epidemiológico em infecções hospitalares, ocorrendo também maior disseminação dessas cepas em outros ambientes. PERESI et al. (2006) em estudo sobre a susceptibilidade antimicrobiana de cepas de $S$. aureus, isoladas de alimentos envolvidos em surtos de doenças bacterianas, encontraram uma cepa ORSA isolada de alimento procedente de confeitaria e outra de padaria. Considerando que os estudos de rastreamento epidemiológico da intoxicação estafilocócica apontam o manipulador de 
alimentos como elemento incisivo no processo de disseminação do microrganismo, existe a possibilidade de que os isolados ORSA em alimentos sejam oriundos de pessoas infectadas. Tal fato confirma a disseminação desses patógenos em ambientes hospitalares e coloca os manipuladores de alimentos como possíveis disseminadores de Staphylococcus ORSA na comunidade, representando risco para a saúde pública. Nesse sentido, é importante efetuar contínua averiguação da sensibilidade desses patógenos a fim de se determinar o aumento dos estafilococos oxacilina-resistentes também na comunidade. Com frequência, o isolamento dessas cepas em ambiente extra-hospitalar está relacionado com o uso prévio de antibióticos, internação recente, atendimento diário em centros médicos e uso de drogas ilícitas por via intravenosa (TAVARES, 2000).

\section{FIGURA 1 - COMPARAÇÃO DA RESISTÊNCIA ANTIMICROBIANA DE SCP POR ANTIBIÓTICOS}

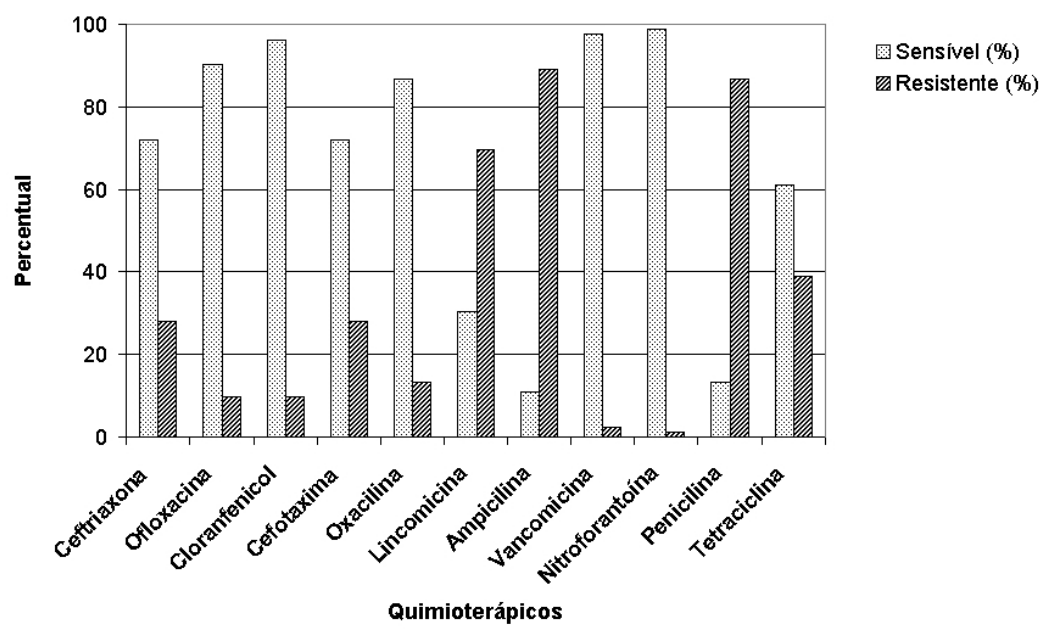

Com relação à snsibiliade, os dados obtidos no presente trabalho mostraram que todas as cepas foram sensíveis ao sulfazotrim (100\%), 98,9\% à nitrofuratoina, $97,6 \%$ à vancomicina, $96,3 \%$ ao cloranfenicol e $90,3 \%$ à ofloxacina. Na avaliação de susceptibilidade de $S$. aureus ZAVADINACK NETTO et al. (2001) constataram maior sensibilidade à vancomicina (100\%), amicacina (100\%), cefoxitina $(100 \%)$, cefalotina $(98,53 \%)$, lincomicina $(98,53 \%)$, gentamicina $(98,2 \%)$, oxacilina $(96,4 \%)$, norfloxacina $(95,77 \%)$ e sulfazotrim $(95,77 \%)$, quando comparados com a penicilina $\mathrm{G}(8,45 \%)$, ampicilina $(8,45 \%)$, tetraciclina $(90,14 \%)$, kanamicina $(81,69 \%)$, eritromicina $(88,41 \%)$ e cloranfenicol $(94,36 \%)$.

PERESI et al. (2006) avaliaram a susceptibilidade antimicrobiana de 25 cepas de $S$. aureus isoladas de alimentos envolvidos em surtos de doenças bacterianas transmitidas por alimentos. Constataram que todos os isolados testados mostraram-se sensíveis à clindamicina, sulfazotrim e vancomicina. Resultados semelhantes foram obtidos por ACCO et al. (2003) trabalhando com cepas de S. aureus isoladas da mucosa nasal de manipuladores de alimentos. Apesar do elevado índice de sensibilidade à vancomicina, $2,4 \%$ das cepas foram resistentes ao antibiótico. Esse fato merece destaque uma vez que a vancomicina é considerada antibiótico de grande eficácia no tratamento de infecções causadas por $S$. aureus. Essa droga, aprovada somente para uso humano, durante anos foi considerada como o único antimicrobiano uniformemente efetivo contra cepas de $S$. aureus resistentes à meticilina. No entanto, o primeiro relato de sua eficácia reduzida foi descrito no Japão em 1997 ao fracassar no combate à infecção humana causada pelo microrganismo (ANDERSON, 1954; MELO et al., 2005).

Grande parte dos estudos sobre a sensibilidade de $S$. aureus destaca a vancomicina como eficaz para o tratamento em infecções (CAETANO et al., 1999; OLIVEIRA et al., 1999; SILVAe GRANJO, 1999; UENO, FARIA e JORGE, 1999). SPIANDORELLO et al. (2001) verificaram que todos os 214 isolados de $S$. aureus de pacientes clínicos e cirúrgicos foram sensíveis à vancomicina. Em contrapartida, 92,6\% foram resistentes à penicilina. Outros trabalhos mostraram o surgimento de 
cepas de S. aureus resistentes ou com sensibilidade intermediária à vancomicina (LIMA et al., 1994; OLIVEIRA et al., 1999; SENA, 2000), corroborando os dados obtidos para duas cepas isoladas que apresentaram resistência a esse antibiótico.

A distribuição das cepas Staphylococcus coagulase positiva não múltiplo resistente (NMR) e de múltiplo resistente (MR) encontra-se na Tabela 2. As cepas MR são definidas como aquelas resistentes para três ou mais quimioterápicos. Das 82 cepas isoladas, uma foi totalmente sensível a todos os antibióticos testados, dez $(12,35 \%)$ se encaixaram no grupo das NMR e setenta e uma $(87,65 \%)$ apresentaram múltipla resistência (MR) a até oito antibióticos. Resistência a seis, sete e oito dos antibióticos testados foi observada, respectivamente, em 7,41\%, 8,64\% e 9,88\% das cepas. ALBUQUERQUE et al. (2007) isolaram cepas de $S$. aureus de manipuladores de peixe e detectaram que $44 \%$ do total apresentou múltipla resistência.

\section{TABELA 2 - PERFIL DE RESISTÊNCIA DAS CEPAS DE Staphylococcus COAGULASE POSITIVA}

\begin{tabular}{|c|c|c|c|}
\hline Perfil de resistência & $\mathrm{N}^{\circ}$ de cepas & $\%$ & Classificação \\
\hline LN & 4 & 4,94 & NMR \\
\hline CRO & 1 & 1,23 & NMR \\
\hline $\mathrm{AP}, \mathrm{PN}$ & 5 & 6,17 & NMR \\
\hline $\mathrm{LN}, \mathrm{AP}, \mathrm{PN}$ & 14 & 17,28 & MR \\
\hline $\mathrm{AP}, \mathrm{PN}, \mathrm{TT}$ & 6 & 7,40 & MR \\
\hline CTX, AP, PN & 2 & 2,47 & MR \\
\hline $\mathrm{CRO}, \mathrm{AP}, \mathrm{PN}$ & 2 & 2,47 & MR \\
\hline$O F X, A P, P N$ & 1 & 1,23 & MR \\
\hline CRO, OFX, LN & 1 & 1,23 & MR \\
\hline $\mathrm{LN}, \mathrm{AP}, \mathrm{PN}, \mathrm{TT}$ & 14 & 17,28 & MR \\
\hline CRO, CTX, AP, PN & 2 & 2,47 & MR \\
\hline $\mathrm{CTX}, \mathrm{LN}, \mathrm{AP}, \mathrm{PN}$ & 3 & 3,70 & MR \\
\hline CRO, CTX, LN, AP & 1 & 1,23 & MR \\
\hline $\mathrm{CRO}, \mathrm{OX}, \mathrm{AP}, \mathrm{PN}$ & 1 & 1,23 & MR \\
\hline CTX, LN, AP, PN & 1 & 1,23 & MR \\
\hline $\mathrm{CO}, \mathrm{LN}, \mathrm{AP}, \mathrm{NT}$ & 1 & 1,23 & MR \\
\hline CRO, LN, AP, PN & 2 & 2,47 & MR \\
\hline CTX, AP, PN, TT & 1 & 1,23 & MR \\
\hline CRO, CTX, AP, PN, TT & 5 & 6,17 & MR \\
\hline CRO, LN, AP, PN, TT & 2 & 2,47 & MR \\
\hline CTX, OX, LN, AP, PN & 2 & 2,47 & MR \\
\hline $\mathrm{CRO}, \mathrm{CO}, \mathrm{LN}, \mathrm{AP}, \mathrm{TT}$ & 1 & 1,23 & MR \\
\hline CRO, OFX, LN, AP, PN & 1 & 1,23 & MR \\
\hline CTX, LN, AP, PN, TT & 1 & 1,23 & MR \\
\hline CRO, CTX, LN, AP, PN & 1 & 1,23 & MR \\
\hline OFX, OX, LN, AP, PN & 1 & 1,23 & MR \\
\hline CRO, OFX, CTX, OX, LN, AP & 1 & 1,23 & MR \\
\hline CRO, OFX, CO, CTX, LN, PN & 1 & 1,23 & MR \\
\hline CRO, CO, CTX, OX, LN, AP, PN & 1 & 1,23 & MR \\
\hline $\mathrm{OX}, \mathrm{AP}, \mathrm{LN}, \mathrm{VC}, \mathrm{NT}, \mathrm{PN}, \mathrm{TT}$ & 1 & 1,23 & MR \\
\hline CRO, OFX, CTX, OX,LN, AP, VC, PN & 1 & 1,23 & MR \\
\hline Total & 81 & 100 & \\
\hline
\end{tabular}

$\mathrm{MR}=$ múltipla resistência; NMR = não múltipla resistência; $\mathrm{AP}=$ ampicilina; $\mathrm{CTX}=$ cefotaxima; $\mathrm{CRO}=$ ceftriaxona; $\mathrm{CO}=$ cloranfenicol; LN = lincomicina; NT = nitrofurantoína; OFX = ofloxacina; $\mathrm{OX}=\mathrm{oxacilina;} \mathrm{PN}=$ penicilina; $\mathrm{TT}=$ tetraciclina; $\mathrm{VC}=$ vancomicina

Um dos primeiros relatos de resistência múltipla foi descrito em 1951, sendo constatadas cepas de Staphylococcus resistentes à penicilina e estreptomicina em dois casos de meningite (ANDERSON, 1954). A presença de cepas de $S$. aureus com resistência múltipla tem sido relatada em hospitais, principalmente para a oxacilina, cloranfenicol, cefalotina e outros antibióticos (UDO et al., 1996). Por outro lado, linhagens isoladas de indústria de alimentos têm apresentado geralmente baixa resistência para as mesmas drogas (TONDO, 2000). 
A múltipla resistência de $S$. aureus resulta da presença de plasmídeos, geralmente em múltiplas cópias, o que garante não somente a sua distribuição durante a divisão celular, mas principalmente permite a transferência em frequência mais elevada sem causar na maioria das vezes custo biológico para a célula bacteriana (PEREIRA et al.,2004).

Mesmo com o desenvolvimento de drogas cada vez mais específicas e de largo espectro, a resistência permanece como problema que requer consideração constante. A elevada ocorrência de resistência múltipla a antibióticos apresenta risco potencial para a saúde pública e pode dificultar o tratamento de doenças humanas e de animais, agravando quadros clínicos potencialmente curáveis (RODRIGUES e VESGA, 2007).

WISTREICH e LECHTMAN, (1980) e MURRAY et al. (1992) citam que devido ao uso incorreto das drogas, os microrganismos (como $S$. aureus) tornam-se resistentes aos agentes e, consequentemente, mais difíceis de serem eliminados. PADILHA (2000) afirmou que a amplitude e frequência da resistência antimicrobiana tornam essa questão significativa para a saúde pública, tendo recebido atenção da Organização Mundial da Saúde (OMS) e da Organização Mundial para a Saúde Animal. De acordo com o CODEX ALIMENTARIUS (2005), o aparecimento e a dispersão das bactérias resistentes ocasionam obstáculos aos procedimentos clínicos e aumentam os custos do tratamento e as taxas de morbidade e mortalidade humana.

\section{CONCLUSÃO}

A ocorrência Staphylococcus coagulase positiva (24\%) nas mãos dos manipuladores de alimentos, associada ao elevado percentual de cepas com resistência múltipla (a até 8 antibióticos) representam sério risco a saúde do consumidor. É de extrema relevância a necessidade de conscientização desses profissionais, mostrando a importância de práticas adequadas de higienização das mãos.

\section{ABSTRACT}

\section{PROFILE RESISTANCE OF POSITIVE COAGULASE Staphylococcus STRAINS} ISOLATED FROM FOOD HANDLERS

In this study, it was investigated the occurrence of positive coagulase Staphylococcus (SPC) strains on the hands of food handlers. The samples were collected from the hands of 100 food handlers that work in a food industry located in the state of Ceará (Brazil). The samples were streaked on plates of Baird-Parker agar. From each plate, typical colonies of Staphylococcus with similar morphologies were picked out and identified by morphologic and biochemical tests. The isolates were tested for antibiotic susceptibility by agar diffusion test. Results indicated Staphylococcus positive coagulase (SPC) presence in $24 \%$ of personnel, being $79,17 \%$ of the women. The isolates were resistant to ampicillin and penicillin ( $89 \%$ and $86,6 \%$, respectively) and were sensitive to sulfazotrim $(100 \%)$, nitrofurantoin $(98.8 \%)$, vancomicyn $(97.6 \%)$, chloranphenicol $(96,3 \%)$ and ofloxacin $(90,3 \%)$. The resistant to ampicilin was observed in $76 \%$ of the isolates were multidrugresistant and one strain was resistant to eight antibiotics. This high occurrence of multiple resistances represents a potential risk for public health and can make difficult to treat human and animal diseases, aggravating potentially curable clinical pictures.

KEY-WORDS: CHEMOTHERAPEUTIC AGENTS; BACTERIAL RESISTANCE; S. aureuS.

\section{REFERÊNCIAS}

1 ACCO, M.; FERREIRA, F.S.; HENRIQUES, J.A.P.; TONDO, E.C. Identification of multiple strains of Staphylococcus aureus colonizing nasal mucosa of food handlers. Food Microbiology, v.20, n.5, p.489-493, 2003.

2 ALBUQUERQUE, W.F; MACRAE, A.; SOUSA, O.V.; VIEIRA, G.H.F.; VIEIRA, R.H.S.F. Multiple drug resistant Staphylococcus aureus strains isolated from a fish. Brazilian Journal of Microbiology, v.38, p.131-134, 2007.

3 ANDERSON, K. A strain of S. aureus resistant to five antibiotics. J. Clin. Path., v. 7, p. 148-151, 1954. 
4 ANDRADE, N.J. de; SILVA, R.M.M. da; BRABES, K.C.S. Avaliação das condições microbiológicas em Unidades de Alimentação e Nutrição. Ciências Agrotécnicas, Lavras, v.27, n.3, p.590-596, maio/jun. 2003.

5 ANDRÉ, M.C.D.P.B; HIDALGO CAMPOS, M.R.; BORGES, L.J.; KIPNIS, A.; PIMENTA, F.C.; SERAFINI, A.B. Comparison of Staphylococcus aureus isolates from food handlers, raw bovine milk and Minas Frescal cheese by antibiogram and pulsed-field gel electrophoresis following Smal digestion. Food Control, v.19, n. 2, p.200-207, Feb. 2008.

6 ARIAS-ECHANDI, M.L. Contaminatión microbiologica de los alimentos en Costa Rica. Una revisión de 10 años. Revista Biomédica, v.11, p.113-122, 2000.

7 ASSUMPÇÃO, E.G; PICOLLI-VALLE, R.H.; HIRSCH, D.; ABREU, L.R. Fontes de contaminação por Staphylococcus aureus na linha de processamento de queijo prato. Arq. Bras. Med. Vet. Zootec., v. 55, n. 3, p.366-370, 2003.

8 BARBOSA, L.; JORGE, A.O.C.; UENO, M. Incidência de Staphylococcus coagulase positiva em leite tipo C e sensibilidade aos antibióticos. Higiene Alimentar, São Paulo, v. 21, n. 148, p. 105-109, jan./fev. 2007.

9 BAUER, A.W.; KIRBY, W.M.M.; SHERRRIS, J.C.; TURCK, M. Antibiotic susceptibility testing by a standardized single disk method. American Journal of Clinical Patholology, v.45, n.4, p.493-496, 1966.

10 BRESOLIN, B.M.Z.; DALL'STELLA, J.K.; FONTOURA-DA-SILVA, S.E. Pesquisa sobre a bactéria Staphylococcus aureus na mucosa nasal e mãos de manipuladores. Estud. Biolog., v.27, n.59, p.27-32, abr./jun. 2005.

11 CAETANO, N.; SOUZA, N.; BURIL, M.; MONTENEGRO, D.; MATOS, D.; CAVALCANTE, V.; PEREIRA, R. Determinação do perfil de sensibilidade e resistência de Staphylococcus na cidade de Recife. In: CONGRESSO BRASILEIRO DE MICROBIOLOGIA, 20., 1999, Salvador. Anais... Salvador: Sociedade Brasileira de Microbiologia, 1999. p.72.

12 CARDOSO, R.C.V.; CHAVES, J.B.P.; ANDRADE, N.J.; TEIXEIRA, M.A. Avaliação da eficiência de agentes sanificantes para mãos de manipuladores de alimentos em serviços de refeição coletiva. Higiene Alimentar, São Paulo, v.10, n. 41, p. 17-22, jan./fev. 1996.

13 CARVALHO, C.O.; SERAFINI, A.B. Grupos de microrganismos isolados da orofaringe, nasofaringe e das mãos dos trabalhadores do restaurante da Universidade Federal de Goiás. Higiene Alimentar, v.10, p.19-24, 1996.

14 CODEX ALIMENTARIUS. Code of practice to minimize and contain antimicrobial resistance. Roma, 2005. (cac/rcp 61- 2005).

15 EVANGELISTA-BARRETO, N.S.; VIEIRA, R.H.S.F. Investigação sobre possíveis portadores de Staphylococcus aureus em duas indústrias de pesca. Higiene Alimentar, v.17, n.104/105, p.49-57, 2003.

16 FELIX, L.F.J. Staphylococcus aureus resistente a oxacilina. Brasília: Centro de Estudos do Hospital Regional da Asa Sul, 2007. 32 p.

17 FIGUEROA, G.G.; NAVARRETE, P.W; CARO, M.C. Portación de Staphylococcus aureus enterotoxigénicos en manipuladores de alimentos. Rev. Méd. Chile, v.130, n. 8, p.859-864, 2002.

18 FRANCO, B.D.G. de M.; LANDGRAF, M. Microbiologia dos alimentos. São Paulo: Atheneu, 2005. 182 p.

19 HOBBS, B.C.; ROBERTS, D. Toxinfecções e controle higiênico-sanitário. In: MANUAL de controle higiênico-sanitário em alimentos. São Paulo: Varela, 1993. cap.9, p.145-152.

20 ICMFS. International Commission on Microbiological Specifications for Food. El sistema de analisis de riesgos y puntos críticos. Zaragoza: Acribia, 1991. p.77-109

21 JAY, J.M. Microbiologia de alimentos. 6.ed. Porto Alegre: Artmed, 2005. 711 p.

22 LIMA, M.P.; CAIFFA FILHO, H.H.; HOSHINO, W.I.; HONDA, R.Y. Identificação de bactérias gram positivas resistentes à vancomicina. Revista Brasileira de Patologia Clínica, v. 30, n.3, p.143-148, 1994.

23 LUES, J.F.R.; TONDER, I. Van. The occurrence of indicator bacteria on hands and aprons of food handlers in the delicatessen sections of a retail group. Food Control, v.18, n.4, p.326-332, 2007

24 MELO, G.B.; MELO, M.C.; GAMA, A.P.; CARVALHO, K.S.; JESUS, T.C.; BONETTI, A.M.; GONTIJO FILHO, P.P. Analysis of genetic diversity of vancomycin-resistant Staphylococcus aureus. Brazilian Journal of Microbiology, v. 36, p. 126-130. 2005.

25 MOURA, A.P.B.L.; ACIOLLI, R.; DUARTE, D.A.M; PINHEIRO JUNIOR, J.W.; ALCÂNTARA, J.S.; MOTA, R.A. Caracterização e perfil de sensibilidade de Staphylococcus spp. isolados de amostras de carne caprina comercializadas em mercados e supermercados em Recife, PE. Arq. Inst. Biol., São Paulo, v.73, n.1, p.7-15, jan./mar. 2006

26 MURRAY, P.R.; DREW, W.L.; KOBAYASHI, G.S.; THOMPSOM, J.H. Microbiologia Médica. Rio de Janeiro: Ed. Guanabara Koogan, 1992. $513 \mathrm{p}$. 
27 NCCLS. National Committee for Clinical Laboratorial Standards. Performance standards for antimicrobial susceptibility testing. Wayne, Pa, 2004. (Supplement M100-S14).

28 OLIVEIRA, C.Z.F.; CORBIA, A.C.G.; NASCIMENTO, M.G.F.; LIGNON, G.B.; SILVA, R.V.M.A. Susceptibilidade antimicrobiana in vitro de bactérias do gênero Staphylococcus, isoladas de queijo minas. Revista Higiene Alimentar, v.13, n.61, p.30, 1999.

29 PADILHA, T. Resistência antimicrobiana x produção animal: uma discussão internacional. Embrapa, Coletânea Rumos e Debates, jun 2000. Disponível em: http://www.embrapa.br:8080/aplic/rumos.nsf $>$ Acesso em:27/01/2009.

30 PEREIRA, M.S.V.; SIQUEIRA JÚNIOR, J.P.; TAKAKI, G.M.C. Eliminação de resistência a drogas por fluorquinolonas em Staphylococcus aureus de origem bovina. Peq. Vet. Bras., v. 24, n. 1, p.11-14, 2004.

31 PERESI, J.T.M.;ALMEIDA, I.A.Z.C.; CARDIGA, E.A.; MARQUES, D.F.; CARNICEL, F.A.;HOFMANN, F.L.Susceptibilidade antimicrobiana de cepas de Staphylococcus aureus e Salmonella spp. isoladas de alimentos envolvidos em surtos de doenças bacterianas transmitidas por alimentos, ocorridos na região noroeste do Estado de São Paulo, no período de abril de 1990 a dezembro de 2003. Rev. Inst. Adolfo Lutz, n. 65, n. 2, p. 112-117, 2006.

32 RODRIGUES, E.A.C.; MENDONÇA, J.S.; AMARANTE, J.M.B.; ALVES FILHO, M.B.; GRINBAAUN, R.S.; NRICTMANN R. Infecções hospitalares: prevenção e controle. São Paulo: Ed Sarvier,1997. 669 p

33 RODRIGUEZ, C.A.; VESGA, O. Staphylococcus aureus resistente a vancomicina. Biomédica, v. 25, p. 575-587, 2005.

34 SENA, M.J. Perfil epidemiológico, resistência a antibióticos e aos conservantes nisina e sistema lactoperoxidase de Staphylococcus sp. isolados de queijos coalho comercializados em Recife-PE. Belo Horizonte, 2000. 74 p. Tese (Doutorado em Ciência Animal) - Escola de Veterinária, Universidade Federal de Minas Gerais.

35 SILVA, N.; JUNQUEIRA, V.C.A.; SILVEIRA, N.F.A. Manual de métodos de análise microbiológica de alimentos. 2. ed. São Paulo: Livraria Varela, 2001. 229 p.

36 SILVA, V.R.; GRANJO, C.A. Ocorrência de Staphylococcus aureus multirresistente em diabéticos. In: CONGRESSO BRASILEIRO DE MICROBIOLOGIA, 20., 1999, Salvador. Anais... Salvador: Sociedade Brasileira de Microbiologia, 1999. p.72.

37 SILVA, W.P.; GANDRA, E.A. Estafilococos coagulase positiva: patógenos de importância em alimentos. Higiene Alimentar, São Paulo, v.18, n.122, p.32-40, jul. 2004.

38 SILVEIRA, G.P.; NOME, F.; GESSER, J.C.; SÁ, M.M. Estratégias utilizadas no combate à resistência bacteriana. Química Nova, v. 29, n. 4, p. 844-855, 2006.

39 SIQUEIRA, R.S. Manual de microbiologia de alimentos. Brasília: Embrapa. 1995. 160 p.

40 SPIANDORELLO, W.P.; MORSH, F.; SEBBEN, S.; SPIANDORELLO, F.S.A. A resistência de Staphylococcus aureus a oxacilina em hospital de Caxias do Sul. Revista AMRIGS, Porto Alegre, v.44, p. 120-125, 2000.

41 TAVARES, W. Bactérias gram-positivas problemas: resistência do estafilococo, do enterococo e do pneumococo aos antimicrobianos. Revista da Sociedade Brasileira de Medicina Tropical, v.33, p. 281-301, 2000.

42 TONDO, E.C.; GUIMARÃES, M.C.M.; HENRIQUES, J.A.P.; AYUB, M.A.Z. Assessing and analyzing contamination of dairy products processing plant by $S$. aureus using antibiotic resistance and PFGE. Can. J. Microbiol., v. 46, p. 136142, 2000.

43 UDO, E.E.; AL-OBAID, I.A.; JACOB, L.E.; CHUGH, T.D. Molecular characterization of epidemic ciprofloxacin and methicillin-resistant $S$. aureus strains colonizing patients in an intensive care unit. J. Clin. Microbiol., v. 34, p. 3242$3244,1996$.

44 UENO, M.; FARIA, I.S.; JORGE, A.O.C. Padrão de resistência a antibióticos em Staphylococcus aureus isolados de crianças saudáveis e de crianças internadas no hospital. In: CONGRESSO BRASILEIRO DE MICROBIOLOGIA, 20., 1999, Salvador. Anais... Salvador: Sociedade Brasileira de Microbiologia, 1999. p.115.

45 VANZO, S.P.; AZEVEDO, R.V.P. Detecção de S. aureus em manipuladores de alimentos - perfil da resistência a antibiótico e quimioterápicos. Higiene Alimentar, v.17, n.104/105, p.114-123, 2003.

46 WISTREICH, G.A.; LECHTMAN, M.D. Microbiologia das doenças humanas. 2. ed. São Paulo: Guanabara-Koogan, 1980. 524 p.

47 ZAVADINACK NETTO, M.; HERREIRO, F.; BANDEIRA, C.O.P.; ITO, Y.; CIORLIN, E.; SAQUETI, E.E.; ANSILIEIRO, I.J.; GONSALVES, L.; SIQUEIRA, V.L.D. Staphylococcus aureus: incidência e resistência antimicrobiana em abscessos cutâneos de origem comunitária. Acta Scientiarum, v. 23, n. 3, p.709-712, 2001. 